\title{
Using Standing Postures as a Practical Alternative to Gait Analysis for Assessing Normal Neuromotor Activity Variation of the Ankle Muscle Antagonists: A Soleus H-reflex and EMG Activity Study Comparing Patients with Hemiplegia to Healthy Subjects
}

\author{
Uso de Posturas Erguidas como Alternativa Práctica al Análisis de Marcha para Evaluar la \\ Actividad Neuromotora Normal de los Antagonistas del Tobillo: Una Comparación entre Pacientes \\ Hemiplégicos y Sujetos Normales
}

Enrique Pineda; M. Sabbahi \& B. Etnyre

PINEDA, E.; SABBAHI, M. \& ETNYRE, B. Using standing postures as a practical alternative to gait analysis for assessing normal neuromotor activity variation of the ankle muscle antagonists: A soleus H-reflex and EMG activity study comparing patients with hemiplegia to healthy subjects. Int. J. Morphol., 28(2):591-594, 2010.

SUMMARY: The purpose of this study was to evaluate and compare the soleus H-reflex amplitudes recorded in three standing postures between a group of patients with stroke and a group of healthy subjects. Nine ambulatory patients were compared with 10 healthy subjects. Measures were recorded during quiet standing (QS), heels raised (PO) and with the foot of the measured leg held just off the ground while standing on the opposite leg (SW). The results showed that patients, as opposed to the healthy group, did not inhibit soleus H-reflex in the SW posture. As opposed to evaluating ankle motor control during gait, the PO and SW standing postures appeared to offer a practical and objective method to assess soleus H-reflex when the purpose is to determine impairment (or recovery) of ankle neuromotor control in stroke survivors.

KEY WORDS: Cerebrovascular accident; Ankle motor control; Soleus H-reflex; Posture.

\section{INTRODUCTION}

The Hoffmann reflex (H-reflex) has long been used as a means of assessing spinal reflex excitability (Magladery and McDougal, 1950; Schiepatti, 1987). Several studies have reported how the soleus H-reflex amplitude varies throughout the phases of gait in healthy subjects (Crenna \& Frigo, 1987; Capaday \& Stein, 1986; Kasai et al., 1998; Morin et al., 1982; Petersen et al., 1999; Llewelyn et al., 1990; Scheneider et al., 2000). These studies, in general, have established that the soleus H-reflex amplitude varies greatly during the course of the gait cycle displaying a similar pattern across healthy subjects. It is enhanced during stance and push-off and almost completely depressed or absent during swing and heel contact. Concurrently, soleus EMG activity is high during stance and at the beginning of the push-off phase. The tibialis anterior (TA) EMG activity is reciprocal to the soleus $\mathrm{H}$ - reflex and soleus EMG activity; it is low during stance and high during heel reception and swing. The inhibition of the soleus motoneuron pool during the swing phase of gait is critical to allow the dorsiflexion of the advancing foot to clear the ground. Motor control at the ankle joint is important for the integrity of walking. Inability to control the ankle joint during the gait cycle (e.g. impaired dorsiflexion) is a common impairment that affects patients with cerebrovascular accidents (CVA) or stroke.

Although soleus H-reflex has been measured in patients with CVA during gait (Leonard et al., 1998; Okuma \& Lee, 1996; Yanagisawa et al., 1976; Yang et al., 1991), it has also been reported the difficulty in obtaining and interpreting reflex and EMG recordings from patients as they

* PT, DPT, PhD, OCS. Physical Therapy Department,The Methodist Sugar Land Hospital, Sugar Land, Texas, USA.

** PT, PhD, ECS. School of Physical Therapy, Texas Woman's University, Houston, Texas, USA.

*** PT, PhD. Department of Human Performance, Rice University, Houston, Texas.USA 
present a broad variability in the extent and severity of gait pattern disruption. This makes each patient to display a unique, but more likely contaminated (e.g., clonus) gait pattern (Yang et al., 1991). Therefore, measures obtained during gait activity may not be the best evaluative paradigm to examine soleus H-reflex in patients with hemiplegia. A previous study showed that the normal variation of the soleus H-reflex could be reproduced by recording it from two standing postures (Pineda et al., 2002. Published Dissertation). Additionally, high reliability $(>.80)$ have been reported for measures of soleus H-reflex amplitudes during single-leg standing (Hopkins et al., 2000) and bipedal quiet standing (Ali \& Sabbahi, 2001; Handcock et al., 2001).

By using postures instead of actual gait, it might be possible to eliminate most of the unwanted contaminants generated from the gait movement itself. The purpose of this study was, therefore, to examine soleus H-reflex amplitudes in patients with CVA while adopting standing postures and compared them to that of healthy subjects.

\section{SUBJECTS AND METHODS}

Subjects. Nine patients with CVA (5 women, 4 men) age range $44-73$ years (mean $+\mathrm{SD}=60.1+8.3$ ) participated in this study. Patients were compared individually and as a group to the pooled data from ten healthy subjects ( 3 women, 7 men), age range 33 - 73 years (mean $+\mathrm{SD}=40.2+12.6$ ). Six patients had left hemiplegia and four patients had right hemiplegia. The onset of the CVAs ranged from 15 to 180 months. Patients were community dwellers able to walk at least 10 meters without stopping, and reported having no diabetes, low back pain, cancer, or orthopedic pathologies. All patients had visited their physicians within the last six months before participating in the study. None of the patients was taking medications to influence muscle tone.

\section{Instrumentation and H-Reflex Recording.}

H-Reflex. H-reflex stimulation and EMG recording were similar to previous published studies (Ali and Sabbahi, 2000; Ali \& Sabbahi, 2001; Al-Rowayeh et al., 2005). Briefly described, the Cadwell 5200A electromyography unit (Cadwell Laboratories, Inc., USA) was used to elicit and record the soleus H-reflex. The tibial nerve was electrically stimulated at the popliteal fossa using 0-5 ms., 0.2 pps pulses at intensity equivalent to H-max. The peak-to-peak amplitude and onset latencies of four separate traces were recorded for each posture.

Experimental Procedure. After the participants read and signed the consent form, soleus H-reflex amplitude recordings were obtained from one leg during each of the following three standing postures: QS: quiet standing; PO: standing with heels raised (Fig. 1); and SW: with the foot of the measured leg just cleared from the ground while standing on the contralateral leg (Fig. 2). Measurements were carried out while all participants rested their hands onto a walker to assist with posture stability. Patients were measured in their affected leg only. Half of the healthy subjects were measured on their right leg and half on their left leg.

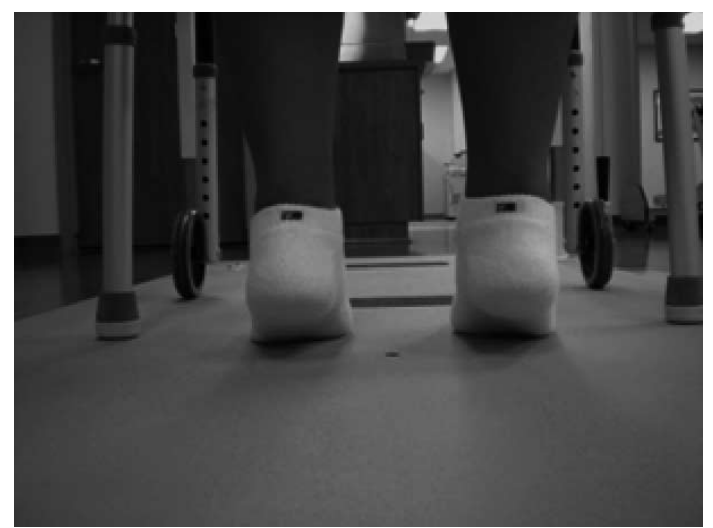

Fig. 1. PO posture.

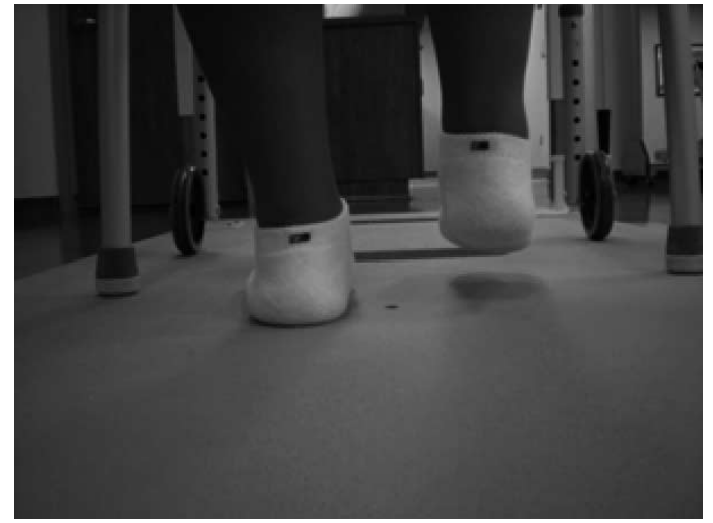

Fig. 2. SW posture.

Signal Data and Statistical Analyses. After eliciting several times the H-reflex and once stability of the amplitudes was ascertained, four peak-to-peak H-reflex amplitudes were recorded and averaged for each posture and for each of the two groups. Latency values were also recorded for each group.

A univariate split-plot one-way repeated measures analysis of variance (ANOVA) was used to assess differences between postures (within-subject factor), and between groups (between-subject factor) for soleus H-reflex amplitude. The dependent variable was soleus H-reflex amplitude. The independent variables were 1) group (healthy subjects and patients), and 2) the standing postures (QS, PO, and SW). 


\section{RESULTS}

The means and standard deviations of the average amplitudes for the healthy subjects and patients are shown in Table I. The average latency for the healthy group was 31 $\mathrm{ms}(\mathrm{SD}=+2.1)$ and for the patients group was $34 \mathrm{~ms}(\mathrm{SD}=$ $+2.1)$.

Table I. Healthy Subjects and Patients- Means and SD of the Hreflex amplitudes (mV).

\begin{tabular}{ccc}
\hline Postures & Healthy Mean + SD & Patients Mean + SD \\
\hline QS & $2.61+2.0$ & $3.37+2.6$ \\
PO & $5.89 \pm 2.7$ & $4.60 \pm 3.1$ \\
SW & $0.92+1.1$ & $3.77+2.6$
\end{tabular}

$\mathrm{QS}=$ quiet standing, $\mathrm{PO}=$ heels raised, $\mathrm{SW}=$ foot of the measured leg held off the ground while standing on the contralateral leg

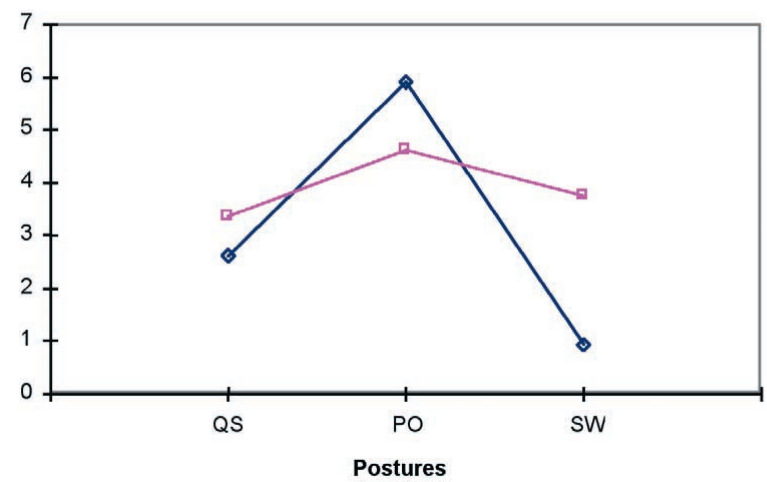

Patients showed the H-reflex being decreased severely or absent in most cases.

Statistical Analyses. The results of the univariate split-plot analysis revealed a statistically significant interaction between posture and group (Fig. 1) The adjusted F (Greenhouse-Geisser method) was: $\mathrm{F}(2.62,55.13)=15.68$, $p<.0005$. The interpretation of the interaction indicated that the effect of posture in soleus H-reflex amplitude depends on group. Follow-up of simple effects revealed that with an alpha level of .016 (with Bonferroni's adjustment procedures), healthy controls and patients were significantly different in the SW ( $\mathrm{p}=.007)$ posture. Inhibition of the soleus $\mathrm{H}$ - reflex did not occur in the (SW) posture in the patients' group.

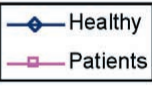

Fig. 3. H-reflex Amplitude (Mv) - Healthy and Patient Groups

\section{DISCUSSION}

As previously reported (Yang et al., 1991), our results showed that the soleus H-reflex amplitude was profoundly disrupted (i.e., lack of inhibition during SW) in patients with CVA. The origins of such inhibition are known to come reciprocally from TA activity to a certain extent (Morin et al., 1982; Yang \& Whelan, 1993), but a more powerful central presynaptic inhibition that begins even before any movement or muscle activity could be detected in the entire leg influences it in a more determinant manner (Morin et al., 1982; Yang \& Whelan, 1993; Scheneider et al., 2000).

This implies an inhibition drive that is non movement dependent.

The average latency found in the patients was slightly higher than that of the healthy subjects, but still under the $35 \mathrm{~ms}$ suggested by Fisher (1992) as the upper limit of normality. Age is related to increased soleus H-reflex latency
(Fisher, 1992), and possibly explains the differences observed between healthy subjects and patients (a 20 year difference in their averaged ages).

In this study, an evaluative paradigm utilizing standing postures was used to examine and compare patients with healthy subjects for soleus H-reflex amplitude. The results showed that the soleus H-reflex was disrupted in the SW posture for the patients as a group. Individual examination, however, showed that in two cases, H-reflex inhibition was nearly normal, corresponding to those individuals with the most recovered, normal appearing gait pattern.

As opposed to evaluating ankle motor control during gait, the PO and SW standing postures appeared to offer a practical and objective method to assess soleus H-reflex when the purpose is to determine impairment (or recovery) of ankle neuromotor control in stroke survivors. 
PINEDA, E.; SABBAHI, M. \& ETNYRE, B. Uso de posturas erguidas como alternativa práctica al análisis de marcha para evaluar la actividad neuromotora normal de los antagonistas del tobillo: Una comparación entre pacientes hemiplegicos y sujetos normales. Int. J. Morphol., 28(2):591-594, 2010.

RESUMEN: El propósito de este estudio fue evaluar y comparar la amplitud de el reflejo H en el músculo sóleo en tres posturas en la posición de pie entre un grupo de pacientes con hemiplejia y un grupo de individuos sanos. Nueve pacientes ambulatorios fueron comparados con diez individuos sanos. Registros fueron obtenidos en la posición de pie bipedal (QS), bipedal con talones elevados (PO), y unipedal manteniendo el pie afectado ligeramente elevado sin contacto con el piso (SW). Los resultados mostraron que los pacientes, en contraste con el el grupo sano, no presentaron inhibición del reflejo H en la postura SW. Comparado a registros del reflejo $\mathrm{H}$ obtenidos durante la marcha, aquellos obtenidos con las posturas PO y SW aparecen como un método más práctico y objetivo para evaluar el reflejo $\mathrm{H}$ del soleus si el propósito es determinar nivel de pérdida (o recuperación) de el control neuromotor del tobillo en pacientes con hemiplejia.

PALABRAS CLAVE: Accidente cerebrovascular; Control motor del tobillo; Reflejo- H sóleo; Postura.

\section{REFERENCES}

Ali, A. A. \& Sabbahi, M. A. H reflex changes under spinal loading and unloading conditions in normal subjects. Clin. Neurophysiol., 111:664-70, 2000.

Ali, A. A. \& Sabbahi, M. A. Test-retest reliability of the soleus Hreflex in three different positions. Electromyogr Clin. Neurophysiol., 41:209-14, 2001.

Alrowayeh, H. N.; Sabbahi, M. A. \& Etnyre, B. Soleus and vastus medialis H-reflexes: similarities and differences while standing or lying during varied knee flexion angles. J. Neurosci. Methods, 15,144(2):215-25, 2005.

Capaday, C. \& Stein, R. B. Amplitude modulation of the soleus Hreflex in the human during walking and standing. J. Neurosci., 6(5):1308-13, 1986.

Crenna, P. \& Frigo, C. Excitability of the soleus H-reflex arc during walking and stepping in man. Exp. Brain Res., 66:49-60, 1987.

Fisher, M. A. AAEM Minimonograph \#13: H reflexes and F waves: Physiology and clinical indications. Muscle Nerve, 15:1223-33, 1992.

Handcock, P. J.; Williams, L. R. T. \& Sullivan, S. J. The reliability of $\mathrm{H}$ reflex in standing subjects. Electromyogr. Clin. Neurophysiol., 41:9-15, 2001.

Hopkins, J. T.; Ingersoll, C. D.; Cordova, M. L. \& Edwards, J. E. Intrasession and intersession reliability of the soleus $\mathrm{H}$ reflex in supine and standing positions. Electromyogr. Clin. Neurophysiol., 40:89-94, 2000.

Kasai, T.; Kawanishi, M. \& Yahagi, S. Posture-dependent modulation of reciprocal inhibition upon initiation of ankle dorsiflexion in man. Brain Res., 792:159-63, 1988.

Leonard, C. T.; Diedrich, P. M.; Matsumoto, T.; Moritani, T. \& McMillan, J. A. H-reflex modulations during voluntary and automatic movements following upper motor neuron damage. Electroencephalogr. Clin. Neurophysiol., 109(6):475-83, 1998.

Llewellyn, M.; Yang, J. F. \& Prochazka, A. Human H-reflexes are lower during beam walking than normal treadmill walking. Exp. Brain Res., 83:22-8, 1990.
Magladery, J. W. \& McDougal, D. B. Electrophysiological studies of nerve and reflex in normal man. Identification of certain reflexes in the electromyogram and the conduction velocity of peripheral nerve fibers. Bull. Johns Hopkins Hospital, 86:26590, 1950.

Morin, C.; Katz, R.; Mazieres, L. \& Pierrot-Deseilligny, E. Comparison of soleus H-reflex facilitation at the onset of soleus contraction produced voluntarily and during the stance phase of human gait. Neurosc. Lett., 33:47-53, 1982.

Okuma, Y. \& Lee, R. G. Reciprocal inhibition in hemiplegia: Correlation with clinical features and recovery. Can. J. Neurol. Sci., 23:15-23, 1996.

Petersen, N.; Morita, H. \& Nielsen, J. Modulation of reciprocal inhibition between ankle extensors and flexors during walking in man. J. Physiol., 520(2):605-19, 1999.

Pineda, E. Evaluation and treatment of patients with stroke: An EMG and H-reflex study. Dissertation Abstracts International (UMI No. 3046315).

Schieppati, M. The Hoffmann Reflex: a means of assessing spinal reflex excitability and its descending control in man. Progr. Neurobiol., 28(4):345-76, 1987.

Schneider, C.; Lavoie, B. A. \& Capaday, C. On the origin of the soleus h-reflex modulation pattern during human walking and its task-dependent differences. J. Neurophysiol., 83(5):2881-90, 2000.

Yanagisawa, N.; Tanaka, R. \& Ito, Z. Reciprocal Ia inhibition in spastic hemiplegia of man. Brain, 99:555-74, 1976.

Yang, J. F.; Fung, J.; Edamura, M.; Blunt, R.; Stein, R. B. \& Barbeau, H. H reflex modulation during walking in spastic subjects. Can. J. Neurol. Sci., 18:443-52, 1991.

Yang, J. F. \& Whelan, P. J. Neural mechanisms that contribute to cyclical modulation of the soleus $\mathrm{H}$ reflex in walking in humans. Exp. Brain Res., 95:547-56, 1993.

Correspondence to:

Dr. Enrique PinedaE. Pineda, PT, DPT, PhD, OCS.

Physical Therapy Department

The Methodist Sugar Land Hospital Received: 09-08-2009 Sugar Land, Texas, USA. 